\title{
PROPRIEDADES QUÍMICAS DE UM CAMBISSOLO CULTIVADO COM CANA-DE-AÇÚCAR, COM PRESERVAÇÃO DO PALHIÇO E ADIÇÃO DE VINHAÇA POR LONGO TEMPO(1)
}

\author{
L. P. CANE LLAS(2), A. C. X. VELLOSO(2), C. R. MARCIANO(2), \\ J . F. G. P. RAMALHO(3), V. M. RUMJ ANEK ${ }^{(4)}$, \\ C. E. REZENDE ${ }^{(5)} \&$ G. A. SANTOS ${ }^{(6)}$
}

\begin{abstract}
RESUMO
0 presente estudo foi realizado a partir de amostras de um Cambissolo Háplico Ta E utrófico vértico, localizado em Campos dos Goytacazes, norte do estado do Rio de J aneiro, e submetido ao cultivo por longo tempo com cana-deaçúcar. E m uma das áreas de coleta, a cana foi cultivada, por 55 anos, sem a queima por ocasião da colheita. Na outra, por 35 anos, houve a adição anual de cerca de $120 \mathrm{~m}^{3} \mathrm{ha}^{-1}$ de vinhaça, por meio de irrigação por aspersão e colheita com a cana queimada. Outras duas áreas, respectivamente adjacentes a essas, onde se realizou a queima por ocasião da colheita durante 55 anos e não se procedeu à adição de vinhaça por 35 anos e colhida com queima do canavial, foram utilizadas para coleta de solo. As amostras foram obtidas nas profundidades de 0-0,20 m e 0,20-0,40 m e tiveram determi nados o pH em água, o fósforo disponível, as bases trocáveis, a capacidade de troca catiônica, a saturação por bases, os teores de micronutrientes, de carbono e de nitrogênio. Realizou-se, ainda, o fracionamento da matéria orgânica humificada. O manejo com cana crua e o com adição de vinhaça aumentaram os teores de macro e micronutrientes, em comparação com o manejo cana queimada e sem adição de vinhaça, respectivamente. Na camada superficial do solo $(0-0,20 \mathrm{~m})$, o teor de carbono variou de $13,13 \mathrm{~g} \mathrm{~kg}^{-1}$, na cana queimada, a $22,34 \mathrm{~g} \mathrm{~kg}^{-1}$, na cana crua, e de $15,71 \mathrm{~g} \mathrm{~kg}^{-1}$, na cana sem adição de vinhaça, a $18,33 \mathrm{~g} \mathrm{~kg}^{-1}$, na cana que anual mente recebeu vinhaça. A melhora nos atributos químicos do solo favoreceu a formação de substâncias húmicas alcalino-solúveis mais polimerizadas.
\end{abstract}

Termos de indexação: ácidos húmicos, ácidos fúlvicos, huminas, manejo do solo, fertilidade, matéria orgânica.

\footnotetext{
(1) Recebido para publicação em novembro de 2002 e aprovado em jul ho de 2003.

(2) Professor do Laboratório de Sol os, Centro de Ciências eTecnol ogias Agropecuárias da Universidade Estadual do NorteF luminense - UENF. Av. Alberto Lamego 2000, Horto, CEP 28013-600 Campos dos Goytacazes (RJ ). E-mail: canellas@uenf.br

(3) Professor da Universidade Federal Rural do Rio de J aneiro- UFRRJ . Campus Leonel Miranda, Estrada do Açúcar, km 5, Penha, CEP 28020-560 Campos dos Goytacazes (RJ).

(4) Professor do Departamento de Química, UFRRJ . E-mail: rumjanek@ufrrj.br

(5) Professor do Laboratório de Ciências Ambientais do Centro de Biociências e Biotecnologia, UENF. E-mail: crezende@uenf.br

(6) Professor do Departamento de Solos, UFRRJ.Bolsista do CNPq. E-mail: gasantos@ufrrj.br
} 


\author{
SUMMARY: CHEMICAL SOIL PROPERTIES OF AN INCEPTISOL UNDER \\ LONG-TERM SUGARCANE CROPS WITH VINASSE \\ APPLICATION AND WITHOUT SLASH BURNING
}

\begin{abstract}
This study was undertaken in Campos dos Goytacazes, northern State of Rio deJ anerro, based on soil samples of a vertic Fluventic Eutrochrepts, which had been cultivated with sugarcane for several decades. In one situation, the crop had been cultivated for 55 years without burning the residues at harvesting. On another sugarcane plantation, harvest residues had been burned, and vinasse inputs applied by sprinkle irrigation at a rate of $120 \mathrm{~m}^{3} \mathrm{ha}^{-1} \mathrm{yr}^{-1}$ during 35 years. Soil samples were collected from the soil layers $0-0,20 \mathrm{~m}$ and 0,20-0,40 $\mathrm{m}$ to evaluateand determi natethepH, avail abl eP, exchangeablebases, cation exchange capacity, double acid extractable micronutrients, total $\mathrm{N}$, and oxidizablecarbon, as well as the fractionation of the humified organic matter. Results indicate that the preservation of crop residueon thesoil surfaceand, to a lesser extent, theaddition of vinasse, increase the macro and micronutrients contents. Carbon contents in the superficial layer $(0-0,20 \mathrm{~m})$ ranged from $13.13 \mathrm{~g} \mathrm{~kg}^{-1}$ in the burned cane to $22.34 \mathrm{~g} \mathrm{~kg}^{-1}$ in the unburned cane, and from $15.71 \mathrm{~g} \mathrm{~kg}^{-1}$ in the cane without vinasse to $18.33 \mathrm{~g} \mathrm{~kg}^{-1}$ in the cane under vinasseapplication. Theimprovement of thechemical soil attri butes favored theformation of more polymerized alkaline-sol uble humic substances.
\end{abstract}

Index terms: humic acids, fulvic acids, humin, soil management, soil fertility.

\section{NTRODUÇÃO}

Ao derrubar a vegetação nativa para instalar plantações, há remoção de sistemas biológicos complexos, multiestruturados, diversificados e estáveis. A sua substituição por sistemas simples e instáveis provoca variações difíceis de quantificar no ciclo dos elementos necessários ao crescimento das plantas, promovendo, geralmente, diminuição da fertilidade do solo.

O entendimento das modificações nas propriedades químicas do solo, decorrentes do cultivo contínuo de cana-de-açúcar, pode fornecer el ementos para produção em bases sustentáveis. O conteúdo e a qualidade da matéria orgânica constituem atributos dos solos que podem ser utilizados para avaliar a sustentabilidade dos sistemas agrícolas (Mielniczuk, 1999). As diferentes frações de carbono orgânico humificado do solo apresentam características químicas, físicas e morfológicas diferenciadas entre si, e a distribuição destas frações no solo podem indicar a qualidade da matéria orgânica. O uso da distribuição relativa das frações dematéria orgânica, como indicador da mudança de manejo do solo ou da qualidade do ambiente, encontra respaldo nos trabalhos de Kononova (1982), Schnitzer \& Khan (1978) e Schnitzer (1991).

A formação das substâncias húmicas é caracterizada por um processo complexo baseado na síntese e, ou, ressíntese dos produtos da mineralização dos compostos orgâni cos que chegam ao solo. É possível, teoricamente, simplificar os vários caminhos da humi ficação em dois mecanismos: a preservação seletiva de biopolímeros e a policondensação de moléculas pequenas (Camargo et al., 1999). Essas transformações incluem um conjunto de reações de oxidação, desidratação, hidrólise, decarboxilação e condensação que são influenciadas pelas condições do solo, tais como: tipo de argila, pH e teor de bases (Zech et al., 1997).

Assumindo qualquer das várias possibilidades para o processo de estabilização dos compostos orgânicos no solo, os ácidos húmi cos representam a fração intermediária entre a estabilização dos compostos pela interação com a matéria mineral (huminas) e a ocorrência de ácidos orgânicos oxidados livres na solução do solo (ácidos fúlvicos livres ou associados). Os ácidos húmicos são, portanto, um marcador natural do processo de humificação e refletem, como tal, tanto a condição de gênese, como de manejo do solo. Solos de ambientes temperados, naturalmente férteis, apresentam teores relativos maiores de ácidos húmicos e valores da relação $\mathrm{C}_{\mathrm{AH}} / \mathrm{C}_{\mathrm{AF}}$ maiores que 1,0 (Kononova, 1982). J á a fração orgânica dos solos tropicais é dominada pelas huminas e, tanto a intensa mineralização dos resíduos, como as restrições edáficas à atividade biológica, tornam os valores da relação $C_{A H} / C_{A F}$ menores do que 1,0 (Dabin, 1981; Ortega, 1982; Canellas et al., 2000).

De acordo com Kononova (1982), os valores da relação $\mathrm{C}_{\mathrm{AH}} / \mathrm{C}_{\mathrm{AF}}$ para solos temperados variam de 0,7 a 2,5. Para sol os tropicais, os val ores médios são mais baixos (Ortega, 1982). Deforma geral, o baixo conteúdo de bases trocáveis nos solos mais intemperizados diminui a intensidade dos processos 
de humificação (condensação e síntese). Em conseqüência, a relação $C_{A H} / C_{A F}$ é menor. $E m$ regiões de temperaturas el evadas, solos com excessiva mobilização e submetidos a queimadas sofrem redução nos teores de matéria orgânica (Alexander, 1977). O teor de carbono no sol o mantém relação direta com a taxa de adição de resíduos orgânicos.

Embora, em curto prazo, problemas de fertilidade possam ser resolvidos com adição de adubos solúveis, alternativas de manejo que preservem teores de carbono no sol o garantem ass boas produções a longo prazo. Trabalhos anteriores relatam o efeito do cultivo contínuo de cana-de-açúcar sobre as propriedades químicas de solos, ocorrendo diminuição considerável na soma de bases (Cerri et al., 1988) ou, dependendo do manejo adotado, elevando a sua fertilidade (Silva \& Ribeiro, 1998).

A utilização de resíduos da indústria, como a vinhaça, já é rotina em muitas regiões canavieiras do País, com aumentos notórios na produção decanade-açúcar (Orlando Filho et al., 1983). Mais recentemente, pressões sociais, para reduzir a emissão de $\mathrm{CO}_{2}$ e de partículas sól idas sobre as áreas urbanas, intensificaram a col heita da cana-de-açúcar sem a queima prévia da palhada (Rio de J aneiro, 1992). Alterações nas propriedades de solos que receberam vinhaça já foram estudadas por Leal et al. (1983), Camargo et al. (1984) e Sengik et al. (1988), e, em áreas não queimadas, por Mendoza et al. (2000). No entanto, nesses estudos, foi considerado um tempo relativamente curto da adoção desses sistemas de manejo do solo.

Este trabal ho teve por objetivo estudar o efeito delongo prazo da preservação da pal hada por ocasião da colheita e da adição de vinhaça sobre as propriedades químicas de um Cambisolo, em áreas com cultivo contínuo de cana-de-açúcar.

\section{MATERIAL E MÉTODOS}

Amostras deum Cambissolo Háplico Ta Eutrófico vértico foram coletadas em duas áreas localizadas entre $41^{\circ} 00^{\prime}$ ' $-41^{\circ} 030^{\prime} \mathrm{W}$ e $21^{\circ} 00^{\prime}$ ' $-21^{\circ} \circ 30^{\prime} \mathrm{S}$, em Campos dos Goytacazes (RJ ). A região apresenta relevo plano, com altitudes mais el evadas de $12 \mathrm{~m}$ em relação ao nível do mar, e é conhecida como Baixada dos Goytacazes (Ravelli Neto, 1989). Apresenta clima Aw (segundo classificação de Köppen), com preci pitação média anual de $1.080 \mathrm{~mm}$ e temperatura média anual entre $24-25^{\circ} \mathrm{C}$.

Na primeira área, desde 1946, não era realizada a queima do canavial por ocasião da colheita e, na segunda, desde 1966, eram adicionados, anualmente, cerca de $120 \mathrm{~m}^{-3} \mathrm{ha}^{-1}$ de vinhaça durante o período de seca no inverno por irrigação por aspersão.
Em áreas adjacentes a ambos os locais, foram col etadas amostras de solo sob cultivo de cana-deaçúcar com a queima por ocasião da col heita e sem a adição de vinhaça, respectivamente. Nos locais com esema adição de vinhaça, a col heita foi realizada com a queima do canavial. A coleta de amostras do solo em ambas as áreas foi realizada em fevereiro de 2001, em duas profundidades (0-0,20 m e 0,20$0,40 \mathrm{~m}$ ), em três amostras compostas formadas por dez amostras simples por área de lavoura de cerca de $492 \mathrm{~m}^{2}$.

Dessa forma, os manejos da lavoura de cana-deaçúcar foram identificados como: (a) cana crua; (b) cana queimada; (c) cana com vinhaça, e (d) cana sem vinhaça. O manejo tradicional da cana-de-açúcar na região nortefluminense inclui o plantio detoletes em sulcos espaçados entre 1 e 1,5 m, controle químico de ervas daninhas e col heita manual. A reforma do canavial é realizada através de aração e gradagem quando a produção atinge cerca de $70 \mathrm{t} \mathrm{ha}^{-1}$ o que, geralmente, ocorre após o quarto corte. A adubação normal mentereal izada nos Cambissol os da Baixada dos Goytacazes é de $60 \mathrm{~kg} \mathrm{ha}^{-1}$ de N, $60 \mathrm{~kg} \mathrm{ha}^{-1}$ de $\mathrm{P}_{2} \mathrm{O}_{5}$ e $60 \mathrm{~kg} \mathrm{ha}^{-1} \mathrm{de}_{2} \mathrm{O}$, numa única vez no plantio (UFRRJ , 1999).

Antes das análises, as amostras de solo foram secas ao ar, destorroadas e passadas em peneiras com abertura de $2 \mathrm{~mm}$ para obtenção da terra fina seca ao ar (TFSA). As análises químicas e físicas foram realizadas, segundo as recomendações da EMBRAPA (1979). O fósforo disponível foi determinado por col orimetria, utilizando o extrator Melhich-1. Os teores dos micronutrientes $\mathrm{Fe}^{3+}, \mathrm{Cu}^{2+}$, $\mathrm{Zn}^{2+}$ e $\mathrm{Mn}^{2+}$ foram obtidos por absorção atômica, á partir do extrato obtido com Melhich-1. O ponto de carga protônica líquida zero (PCPLZ) foi determinado medindo-sea adsorção de $\mathrm{H}^{+} \mathrm{eOH}^{-}$nas amostras do solo (Sposito, 1989). O fracionamento da matéria orgânica foi realizado a partir da simplificação do método de Belchikova-Kononova, descrito em detalhes em Guerra \& Santos (1999), ou seja, amostras de TFSA sofreram prétratamento com ácido ortofosfórico $2 \mathrm{~mol} \mathrm{~L}^{-1}$, que separou por densidade a fração leve e solubilizou a fração ácidos fúlvicos livres (AFL).

Em seqüência, sobre a amostra de TFSA, foi col ocada a mistura extratora de $\mathrm{NaOH} 0,1 \mathrm{~mol} \mathrm{~L}^{-1}+$ $\mathrm{Na}_{4} \mathrm{P}_{2} \mathrm{O}_{7} 0,1 \mathrm{~mol} \mathrm{~L}-1$, na proporção $1: 10(\mathrm{v} / \mathrm{v})$, que solubilizou os ácidos fúlvicos (AF) eos ácidos húmicos $(\mathrm{AH})$. O resíduo sólido insolúvel resultante do processo de fracionamento foi denominado huminas (H). Os AH foram separados dos AF por centrifugação, após precipitação em meio ácido obti do com adição de $\mathrm{H}_{2} \mathrm{SO}_{4}$ concentrado até o val or de $\mathrm{pH}$ 1. O teor de carbono em cada fração foi determinado por meio de dicromatometria. O quadro 1 mostra uma possibilidade de interpretação do fracionamento da matéria orgânica. Deve-se levar em conta, ainda, que os valores obtidos para 
Quadro 1. Critérios para interpretação do fracionamento químico da matéria orgânica

\begin{tabular}{|c|c|c|c|c|c|}
\hline \multirow{2}{*}{ Parâmetro } & \multicolumn{5}{|c|}{ Limite de interpretação } \\
\hline & Muito forte & Forte & Moderado & Fraco & Muito fraco \\
\hline$C_{\text {total }}\left(\mathrm{g} \mathrm{kg}^{-1}\right)$ & $>50$ & $25-50$ & $10-25$ & $10-5$ & $<5$ \\
\hline \multicolumn{6}{|c|}{ Teor de huminas em relação ao carbono total do solo } \\
\hline $\mathrm{C}_{\mathrm{H}}$ & $>75 \%$ & $60-75 \%$ & $45-60 \%$ & $<45 \%$ & - \\
\hline \multicolumn{6}{|c|}{ Percentagem relativa à soma das frações alcalino-solúveis } \\
\hline $\mathrm{C}_{\mathrm{AF}}+\mathrm{C}_{\mathrm{AH}}$ & $>20 \%$ & $10-20 \%$ & $5-10 \%$ & $2,5-5 \%$ & $<2,5 \%$ \\
\hline $\mathrm{C}_{\mathrm{AH}} / \mathrm{C}_{\mathrm{AF}}$ & \multicolumn{5}{|c|}{$\begin{array}{l}\text { Valores próximos à unidade } \\
\text { Valores inferiores podem indicar má evolução por razões edáficas ou de manejo ou adição recente } \\
\text { de matéria orgânica }\end{array}$} \\
\hline
\end{tabular}

Adaptado de Dabin (1981), Kononova (1982) e Labrador (1996).

cada fração de carbono humificado são relativos e só comparáveis entre si se o procedimento de fracionamento de matéria orgânica for o mesmo.

As alterações nas propriedades químicas e granulométricas do solo foram estudadas por meio do delineamento inteiramente casualizado (com os tratamentos cana crua, cana queimada, cana com vinhaça e cana sem vinhaça). A análise da variância foi realizada pelo testeF e, quando cabível, as médias foram comparadas pelo teste de Tukey a $5 \%$, pelo programa computacional Sistema de Análises Estatísticas e Genéticas (SAEG), desenvolvido pela Universidade Federal de Viçosa.

\section{RESULTADOS E DISCUSSÃO}

No quadro 2, encontram-se os valores da análise química e granulométrica do solo, nas duas profundidades estudadas. Observa-se que a reação do solo não apresentou variação significativa com os diferentes tipos de manejo da lavoura de canade-açúcar, mesmo com o longo tempo de produção, resultados estes semel hantes aos obtidos por Silva \& Ribeiro (1998). O cultivo continuado de cana crua e cana com vinhaça col hida com a queima alterou significativamente os teores de ${ }^{+} \mathrm{eCa}^{2+}$ na camada superficial, em relação aos valores obtidos na área de cana quei mada com 55 anos decultivo ou de cana quei mada sem vinhaça com 35 anos de cultivo $(1,5$ e $0,81 \mathrm{cmol}_{\mathrm{C}} \mathrm{dm}^{-3}$ e 8,3 e $5,3 \mathrm{cmol}_{C} \mathrm{dm}^{-3}$, respectivamente).

Constatou-se que os teores desses nutrientes aumentaram em profundidade na área de cana crua em relação à cana quei mada, mas não foram alterados na área de cana com vinhaça, o que seria esperado mediante a percolação do resíduo no solo. As variações nos teores de $\mathrm{Mg}^{2+}$ foram estatisticamente significativas e maiores nas áreas de cana crua e de cana com vinhaça, em comparação com os valores obtidos nas áreas de cana queimada e cana sem vinhaça. O teor de $\mathrm{Na}^{+}$trocável foi significativamente maior, nas duas camadas de solo, na área com cana crua em relação aos obtidos na área de cana queimada.

A CTC efetiva apresentou valores inferiores aos da capacidade de troca determinada (CTC) em decorrência da geração de cargas negativas no solo com o aumento do $\mathrm{pH}$ para 7,0 no método do cátion índice. Esse efeito foi maior na área de cana crua, graças, provavelmente, ao maior aporte anual de carbono. A CTC efetiva e a CTC em pH 7,0 foram alteradas significativamente após 55 anos de preservação da palhada sobre a superfície do solo (Quadro 2). Os aumentos foram de 57 e de $68 \%$, nas camadas de 0-0,20 me 0,20-0,40 m, respectivamente, em comparação aos val ores encontrados na área de cana queimada. Nas áreas de cana com vinhaça, também foi observado aumento significativo da CTC na camada superficial, porém em menor magnitude (8\%), quando comparado com os val ores observados na área de cana sem vinhaça.

Na camada subsuperficial, não foi observado aumento da CTC com a adição de vinhaça. Houve uma correlação muito significativa $(p<0,01)$ entre a CTC efetiva e o teor de carbono orgânico oxidável do solo (Figura 1), indicando que parte da variação da CTC é devida à matéria orgânica. A contribuição da matéria orgânica para CTC dos sol os éimportante e foi estimada entre 56 e $82 \%$ da CTC de solos sob condições tropicais (Raij, 1981), o que favorece a retenção de cátions e diminui as perdas por lixiviação. Nos solos de mineralogia predominantemente 1:1, a matéria orgânica do solo comanda o desenvolvimento de cargas na superfície, sendo 
natural a maior capacidade de troca encontrada nas áreas de maior aporte de matéria orgânica.

Independentemente da sua natureza, a adição de resíduos orgânicos ao sol o causou o abaixamento do ponto de carga protônica líquida zero (PCPLZ), nas duas profundidades estudadas (Quadro 2). As variações encontradas no PCPLZ eram esperadas e importantes na geração de cargas negativas no solo, uma vez queadsorção de ânions reduz a quantidade de sítios ácidos disponíveis, deslocando o PCPLZ para valores menores (Siqueira et al., 1990). A acidez potencial $(\mathrm{H}+\mathrm{Al})$ foi dominada exclusivamente pelos íons $\mathrm{H}^{+}$, uma vez que não foi possível detectar o $\mathrm{Al}^{3+}$. A acidez potencial foi maior na camada superficial nas áreas com menor teor de carbono, indicando que a oxidação da matéria orgânica pode ser um componente importantena geração da acidez.

Foi observada uma grande e significativa diferença no teor de fósforo disponível (Melhich-1) nas amostras de solo das áreas cultivadas com cana crua. Além do efeito cumulativo da aplicação de nutrientes no sol o pel os fertilizantes, observado por

Quadro 2. Valores obtidos para as análises, química e granulométrica, de um Cambissolo Háplico Ta E utrófico vértico, em Campos dos Goytacazes (RJ ), submetido ao manejo de cana crua, cana queimada, cana com aplicação de vinhaça e cana sem aplicação de vinhaça

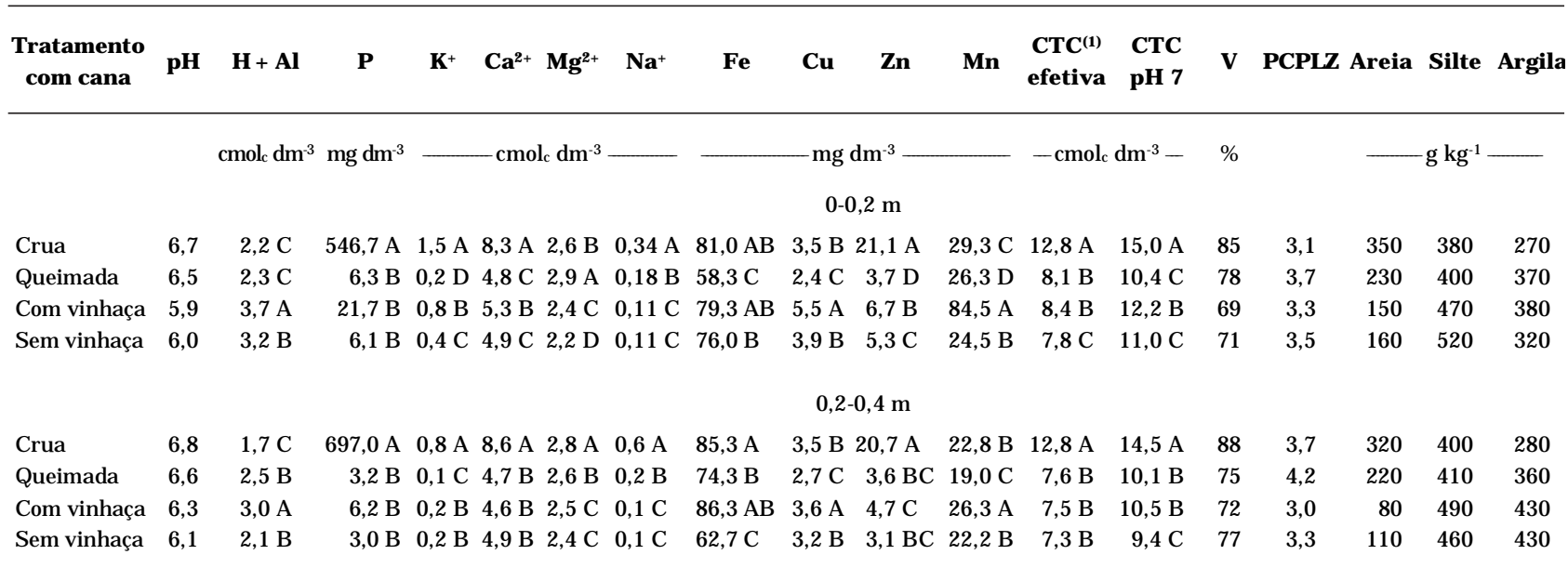

Médias seguidas de letras iguais, na coluna, em cada profundidade não diferem estatisticamente pelo teste de Tukey $(p<0,05)$. Médias sem letras, nas colunas, indicam ausência de significância pelo teste $\mathrm{F} .{ }^{(1)}$ Valores de $\mathrm{Al}^{3+}$ são nulos.
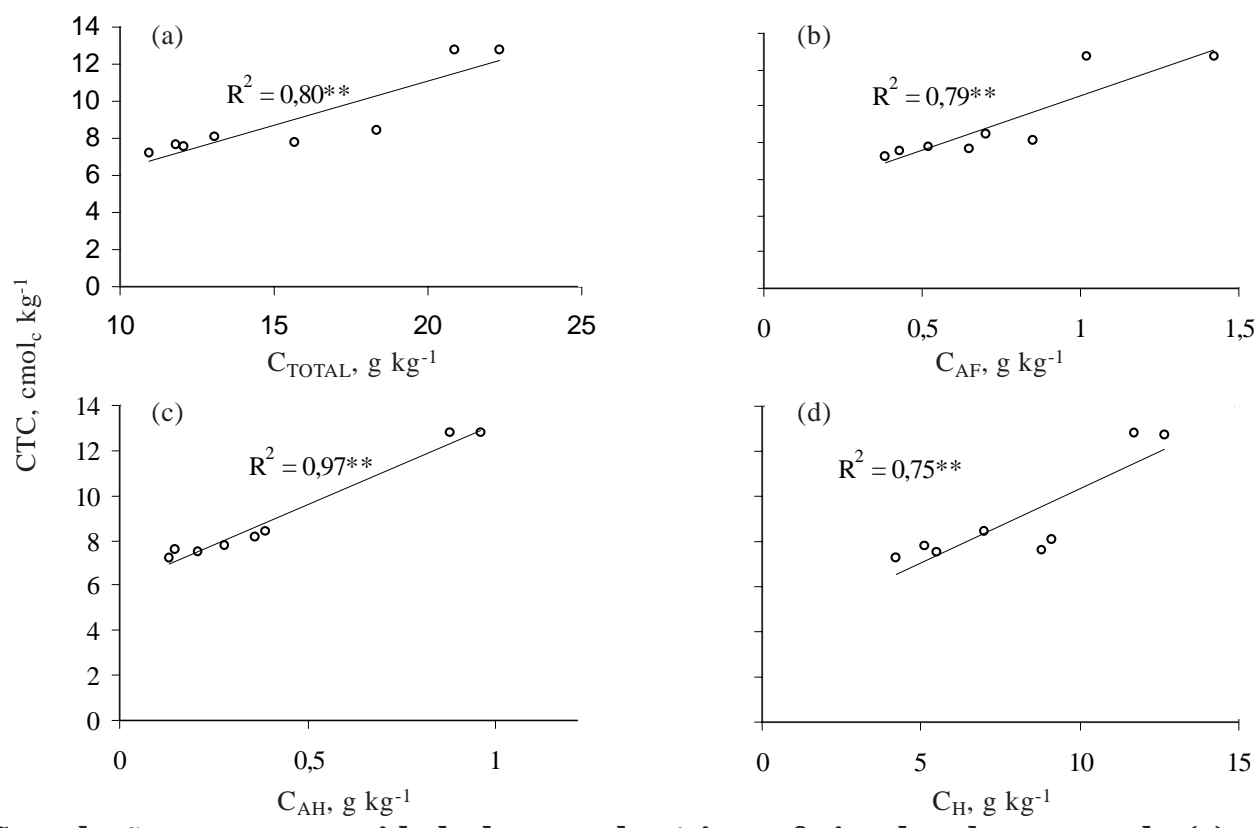

Figura 1. Correlação entre a capacidade de troca de cáti ons efetiva do solo e teores de: (a) carbono oxidável - $\mathrm{C}_{\text {total; }}$ (b) ácidos fúlvicos - $\mathrm{C}_{\mathrm{AF}} ;(\mathrm{c})$ ácidos húmicos - $\mathrm{C}_{\mathrm{AH}}, \mathrm{e}(\mathrm{d})$ huminas - $\mathrm{C}_{\mathrm{H}}$. 
outros autores (Silva \& Ribeiro, 1998), o retorno das formas de fósforo acumuladas na biomassa vegetal pode contribuir para o aumento observado. Na área de cana com vinhaça, oteor de P disponível também foi estatisticamente maior do que o da área de cana sem vinhaça (Quadro 2).

Korndorfer \& Alcarde (1992) verificaram efeito residual do fertilizantefosfatado com disponibilidade de até $30 \%$ do fertilizante aplicado na forma disponível depois de 34,5 meses de incorporação ao sol o. Por meio do fracionamento seqüencial, Araújo \& Salcedo (1997) constataram que o P considerado como disponível foi a forma mais acumulada em sol os cultivados com cana-de-açúcar. J á é bastante conhecida a importância dos compostos orgânicos que contêm fósforo na fração $P$ considerada disponível (Guerra et al., 1996).

Os teores dos mi cronutrientes estudados também foram maiores nas áreas onde se preservou a pal hada na hora da col heita, independentemente da profundidade do solo, quando comparado ao manejo com a queima do canavial. Na área de cana com vinhaça, houve acréscimo significativo nos teores de $\mathrm{Cu}^{2+}, \mathrm{Zn}^{2+}$ e $\mathrm{Mn}^{2+}$, na camada de solo de 0-0,20 m, e de $\mathrm{Cu}^{2+}$ e $\mathrm{Fe}^{3+}$, na camada de 0,20-0,40 m.

A vinhaça na região de Campos dos Goytacazes, além de matéria orgânica, revelou altos teores de $\mathrm{Zn}^{2+}, \mathrm{Mn}^{2+} \mathrm{eCu}^{2+}$ (Bolsanello \& Vieira, 1980) e sua aplicação num Cambissolo localizado em CamposRJ aumentou principalmente os teores de $\mathrm{Zn}^{2+}$ (Ramalho \& Amaral Sobrinho, 2001). Reis \& Monnerat (2002) avaliaram a condição nutricional dos canaviais da região de Campos dos Goytacazes
(RJ ) e encontraram os elementos P, K, S, Zn e Cu como os mais limitantes. Com exceção do enxofre, que não foi determinado neste trabalho, todos os outros elementos citados por Reis \& Monnerat (2002) tiveram seus teores aumentados no sistema cana crua e no sistema cana com vinhaça, em comparação aos sistemas cana quei mada e cana sem vinhaça. A preservação da pal hada ea adição de vinhaça podem ser uma estratégia importante na manutenção e aumento da fertilidade do solo a longo prazo em lavouras de cana.

Os teores de carbono, nitrogênio e de carbono das frações humi ficadas da matéria orgânica do sol o nas áreas sob cultivo contínuo de cana-de-açúcar encontram-se no quadro 3. Comparando o efeito de longa duração do manejo cana crua com o manejo cana queimada, verifica-se um acréscimo da ordem de 70 e $77 \%$ de carbono na camada superficial e subsuperficial, respectivamente.

Além do efeito direto da preservação da matéria orgânica na forma de resíduos vegetais na superfície do solo, que natural mente favorece a concentração de carbono, nas áreas de cana crua, a lavoura fica mais tempo sem renovação. O tempo médio de renovação da lavoura na região norte fluminense é de cerca de 4 cortes, de acordo com a sua produtividade. $\mathrm{Na}$ área de cana crua, esse tempo é pel o menos o dobro e, no final do período estudado, cerca de 12 anos sem renovação.

A movimentação e o preparo do sol o para o cultivo (aração, gradagem e abertura de sulcos) favorecem as reações de oxidação, por meio do aumento da pressão parcial de oxigênio $\left(\mathrm{PO}_{2}\right)$ e da exposição de

Quadro 3. Teores de carbono (C), nitrogênio (N), relação $C / N$, teores de carbono nas frações ácidos fúlvicos livres $\left(\mathrm{C}_{\mathrm{AFL}}\right)$, ácidos fúlvicos $\left(\mathrm{C}_{\mathrm{AF}}\right)$, áci dos húmicos $\left(\mathrm{C}_{\mathrm{AH}}\right)$, relação ácidos fúlvicosaácidos húmicos $\left(\mathrm{C}_{\mathrm{AH}} /\right.$ $\mathrm{C}_{\mathrm{AF}}$ ) e grau de humificação (GH) da matéria orgânica de um Cambissolo Háplico Ta E utrófico vértico de Campos dos Goytacazes (RJ ), submetido ao manejo de cana crua, cana queimada, cana com aplicação de vinhaça e cana sem aplicação de vinhaça

\begin{tabular}{|c|c|c|c|c|c|c|c|c|c|}
\hline $\begin{array}{l}\text { Tratamento } \\
\text { com cana }\end{array}$ & C & $\mathbf{N}$ & $\mathbf{C} / \mathbf{N}$ & C & $\mathbf{C}_{\mathrm{AF}}$ & $\mathbf{C}_{\mathbf{A H}}$ & $\mathbf{C}_{\mathbf{H}}$ & $\mathbf{C}_{\mathrm{AH}} / \mathbf{C}_{\mathrm{AF}}$ & GH \\
\hline & \multicolumn{3}{|c|}{$\mathrm{g} \mathrm{kg}^{-1}$} & \multicolumn{4}{|c|}{$\mathrm{kg}^{-1}$} & & $\%$ \\
\hline & & & & & $0-0,2 \mathrm{~m}$ & & & & \\
\hline Crua & $22,34 \mathrm{~A}$ & $2,2 \mathrm{~A}$ & $10,14 \mathrm{~A}$ & $0,22 \mathrm{~A}$ & $1,02 \mathrm{~A}$ & $0,96 \mathrm{~A}$ & $12,72 \mathrm{~A}$ & $0,94 \mathrm{~A}$ & $67 \mathrm{~B}$ \\
\hline Queimada & $13,13 \mathrm{C}$ & $1,5 \mathrm{~B}$ & $8,72 \mathrm{~B}$ & $0,21 \mathrm{~A}$ & $0,85 \mathrm{~B}$ & $0,36 \mathrm{~B}$ & $9,15 \mathrm{~B}$ & $0,42 \mathrm{~B}$ & $80 \mathrm{~A}$ \\
\hline Com vinhaça & $18,33 \mathrm{~B}$ & $1,8 \mathrm{~B}$ & 8,74 B & $0,23 \mathrm{~A}$ & $0,70 \mathrm{~B}$ & $0,39 \mathrm{~B}$ & $7,01 \mathrm{~B}$ & $0,56 \mathrm{~B}$ & $45 \mathrm{C}$ \\
\hline \multirow[t]{2}{*}{ Sem vinhaça } & $15,71 \mathrm{C}$ & $1,8 \mathrm{~B}$ & $10,23 \mathrm{~A}$ & $0,16 \mathrm{~B}$ & $0,52 \mathrm{C}$ & $0,28 \mathrm{C}$ & $5,13 \mathrm{C}$ & $0,54 \mathrm{~B}$ & $39 \mathrm{C}$ \\
\hline & & & & & $0,2-0,4 \mathrm{~m}$ & & & & \\
\hline Crua & $20,95 \mathrm{~A}$ & $2,13 \mathrm{~A}$ & $10,02 \mathrm{~A}$ & $0,24 \mathrm{~A}$ & $1,42 \mathrm{~A}$ & $0,88 \mathrm{~A}$ & $11,74 \mathrm{~A}$ & $0,62 \mathrm{~A}$ & $68 \mathrm{~B}$ \\
\hline Queimada & $11,81 \mathrm{C}$ & $1,45 \mathrm{~B}$ & 8,43 B & $0,24 \mathrm{~A}$ & $0,65 B$ & $0,15 \mathrm{C}$ & $8,85 B$ & $0,23 \mathrm{~B}$ & $83 \mathrm{~A}$ \\
\hline Com vinhaça & $12,12 \mathrm{~B}$ & $1,65 \mathrm{~B}$ & $7,65 \mathrm{~B}$ & $0,13 \mathrm{~B}$ & $0,43 \mathrm{~B}$ & $0,21 \mathrm{~B}$ & $5,54 \mathrm{~B}$ & $0,49 \mathrm{~A}$ & $52 \mathrm{~B}$ \\
\hline Sem vinhaça & $10,90 \mathrm{C}$ & $1,42 \mathrm{~B}$ & $7,80 \mathrm{~B}$ & $0,15 \mathrm{~B}$ & $0,38 \mathrm{C}$ & $0,13 \mathrm{C}$ & $4,25 \mathrm{C}$ & $0,21 \mathrm{~B}$ & $45 \mathrm{~B}$ \\
\hline
\end{tabular}


novas superfícies para o ataque microbiano. 0 bal anço líquido desse efeito éa diminuição dos teores de matéria orgânica nos sistemas com preparo de sol o mais intensivo. Sistemas mais conservacionistas tendem, com o tempo, a apresentar um incremento de matéria orgânica na superfície do solo (Testa et al., 1992; F reixo et al., 2002).

Nas áreas de cana queimada, onde se comparou o efeito da adição ou não de $120 \mathrm{~m}^{3}$ ha-1 de vinhaça durante cerca de 35 anos, também se verificou acréscimo nos teores de carbono do solo na área de cana com vinhaça. Embora menos pronunciado que na área de cana crua, este acúmul o foi significativo e na ordem de 17 e $11 \%$ de carbono orgânico, nas camadas de 0-0,20 e 0,20-0,40 m, respectivamente. A rápida decomposição da matéria orgânica da vinhaça quando atinge o solo já foi verificada por outros autores (Tedesco et al., 1999). O resultado é o menor incremento no teor de carbono quando comparado aos obtidos com o sistema cana crua. Entretanto, acréscimos médios de $14 \%$ de carbono não são desprezíveis para solos tropicais, onde é notadamente difícil aumentar os teores de matéria orgânica no solo.

Os teores de nitrogênio do solo também foram alterados de acordo com os sistemas de manejo utilizados no cultivo da cana-de-açúcar. Na área de cana crua, ocorreu aumento de 47 e de $50 \%$ nos teores de $\mathrm{N}$ nas camadas entre $0-0,20$ e 0,20-0,40 m, respectivamente, em relação aos valores obtidos na área de cana queimada. A adição de vinhaça não alterou os teores de N no solo, em comparação com a área sem adição do resíduo.

Os valores da relação $\mathrm{C} / \mathrm{N}$ do solo nas áreas estudadas variaram de 7,6 a 10,2, mostrando a presença de matéria orgânica estável. Calasans (1998), estudando a composição el ementar (C/N) e isotópica do carbono orgânico em diferentes grupos de sol os sob pastagem, cana-de-açúcar com queima durante a col heita e sem adição de vinhaça e mata, encontrou valores da relação $\mathrm{C} / \mathrm{N}$ do solo de 12,8 a 13,2; de 10,9 a 16,0 e de 9,52 a 13,9, respectivamente.

Os teores de carbono das frações humificadas da matéria orgânica do solo são apresentados no quadro 3. A fração ácidos fúlvicos livres $\left(\mathrm{C}_{\mathrm{AFL}}\right)$ representa a menor parte do conteúdo total de carbono em todas as áreas estudadas. Na fração ácidos fúlvicos $\left(\mathrm{C}_{\mathrm{AF}}\right)$, foi observado acréscimo na ordem de $13 \%$ na área de cana com vinhaça na camada subsuperficial, em comparação com a área de cana sem vinhaça. A diminuição dos teores de $\mathrm{C}_{\mathrm{AFL}}$ e o aumento na fração de $\mathrm{C}_{\mathrm{AF}}$ podem indicar tanto a evolução química dos compostos orgânicos com a humificação, como o transporte dessa fração para camadas de solo mais profundas. Nas áreas onde se comparou o efeito da cana crua com a cana queimada, verificou-se um acréscimo de $118 \%$ no $\mathrm{C}_{\mathrm{AF}}$ na maior profundidade estudada.
Outros estudos já constataram a mobilidade dessa fração humificada de carbono no perfil do solo (Canellas et al., 2000). Apesar de a fração ácidos húmicos $\left(\mathrm{C}_{\mathrm{AH}}\right)$ representar quantitativamente os menores teores de carbono humificado, esta sofreu as maiores alterações relativas, com um acréscimo de $116 \%$, no $C_{A H}$ em superfície, e de $486 \%$, em subsuperfície, nas áreas decana crua, em comparação com a área de cana queimada.

No sistema de cana com vinhaça também foram observados aumentos nos teores de $\mathrm{C}_{\mathrm{AH}}$, porém em menor escala (40 e $61 \%$ nas camadas de 0-0,20 e 0,20-0,40 m, respectivamente), em comparação com os valores de cana em vinhaça.

Os resultados comprovam não só a existência de mobilidade não esperada da fração ácidos húmicos, mas também a melhora da fertilidade do solo nos sistemas de maior aporte de matéria orgânica que pode favorecer a condensação das frações al calinosolúveis. Com exceção da fração $C_{A F L}$, todas as frações de carbono apresentaram correlação significativa com a CTC efetiva do solo (Figura 1) e melhor ajuste $\left(R^{2}=0,97\right)$ obtido justamente com a fração $C_{A H}$. A fração humificada residual (huminas) teve seus teores médios aumentados em cerca de $35 \%$ em termos médios nas áreas de cana crua e cana com vinhaça, independentemente da profundidade do solo.

A figura 2 mostra a composição relativa da matéria orgânica humificada por meio da participação de cada fração na distribuição total do carbonohumificado $\left(\mathrm{C}_{\mathrm{AFL}}+\mathrm{C}_{\mathrm{AF}}+\mathrm{C}_{\mathrm{AH}}+\mathrm{C}_{\mathrm{H}}=100 \%\right)$. Nota-se que as frações al cal ino-solúveis $\left(\mathrm{C}_{\mathrm{AF}}+\mathrm{C}_{\mathrm{AF}}\right.$ $+\mathrm{C}_{\mathrm{AH}}$ ) são a menor parte, não excedendo $20 \%$ do carbono humificado. Entre 84 e $89 \%$ do carbono humificado está contido na fração humina. Nas áreas de cana com e sem vinhaça, verifica-se que, na camada de 0-0,20 m, a composição da fração humificada no solo foi a mesma. Pequenas modificações foram verificadas na camada mais profunda de solo, onde se notou ligei ro aumento nas frações alcalino-solúveis das menos para as mais polimerizadas ( $\mathrm{AFL} \rightarrow \mathrm{AF} \rightarrow \mathrm{AH}$ ) com a adição de vinhaça. J á entre os sistemas cana crua e cana quei mada, as diferenças na distribuição do carbono humificado foram mais acentuadas.

Nas amostras de solo retiradas da área de cana crua, a distribuição da fração alcalino-solúvel correspondeu a 1,5\% como ácidos fúlvicos livres, 6,8 \% como ácidos fúlvicos e 6,4 \% como ácidos húmicos e, na área de cana queimada, os teores dessas frações foram de 2,0, 8,1 e 3,4 \%, respectivamente. Na camada de 0,20-0,40 m, tais diferenças mostraram-se acentuadas. A exceção foi a fração AF, maior na área de cana crua, correspondendo a cerca de $10 \%$ do carbono humificado. Mudanças na distribuição percentual das frações expressam a qualidade do húmus e a dinâmica do processo de humificação. Na área de 


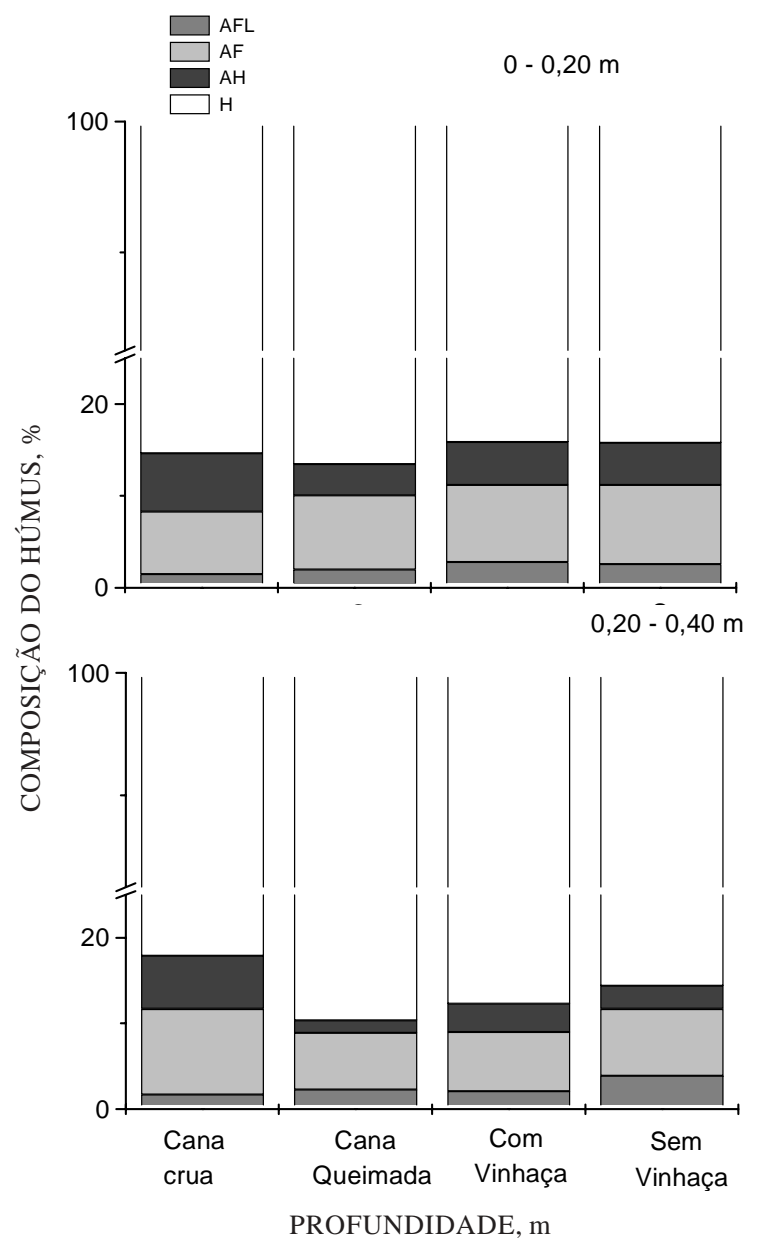

Figura 2. Distribuição percentual das frações humificadas da matéria orgânica do solo: $100 \%=C_{A F L}+C_{A F}+C_{A H}+C_{H}$, onde $C_{A F L}, C_{A F}$, $C_{A H}$ e $C_{H}$ representam os teores de carbono contido nas frações ácidos fúlvicos livres, ácidos fúlvicos, ácidos húmicos e huminas, respectivamente.

cana crua, que proporcionou acúmulo de matéria orgânica do solo, foram observados os maiores valores para a relação $C_{A H} / C_{A F}$.

A maior parte do húmus nas amostras de solo estudadas é composta pela fração humina, o que também foi observado por Dabin (1981) em outros sol os tropicais brasileiros e africanos, e atribuído à rápida insolubilização dos resíduos vegetais que chegam ao solo. Uma série de fatores, tais como: a interação com a fração mineral de natureza oxídica e as reações de desidratação favorecidas pela alternância de períodos secos e úmidos, favorecem a formação de huminas. J á a predominância de ácidos fúlvicos no extrato alcalino, segundo Mendonça \& Rowell (1994), pode ser justificada através da formação de complexos que resulta na maior preservação e proteção dessa fração ao ataque microbiano. O aumento dos teores deácidos húmicos nas áreas de cana crua e cana com vinhaça foi acompanhado da mel hora geral na fertilidade do solo (Quadro 2).

De acordo com Silva et al. (2000), a maior prevalência de ácidos fúlvicos nos solos de reação ácida pode resultar, a longo prazo, em ambientes menos favoráveis à atividade microbiana, com concomitante redução na fertilidade do solo.

Os resultados obtidos corroboram essa hipótese. Borges \& Kiehl (1996) verificaram que, quanto mais intenso o manejo do solo, menor foi o seu conteúdo de ácidos húmicos. Mendoza et al. (2000) também avaliaram o efeito da preservação da palhada de cana-de-açúcar sobre a distribuição da matéria orgânica humificada de um Argissolo de tabuleiro, tendo observado somente aumento na fração $C_{A F}$. Os resultados obtidos na presente pesquisa, com maior tempo de preservação da palhada, evidenciaram que, com o tempo, devem ocorrer a condensação da fração al calino-solúvel e o acúmulo de ácidos húmicos, com melhorias na qualidade da matéria orgânica do solo.

Nos sistemas com maior aporte de matéria orgânica, como nos de cana crua e cana com vinhaça, é possível indicar alguns benefícios ambientais e econômicos, tais como: a diminuição dos custos de renovação do canavial, decorrente de sua maior Iongevidade; a disposição de resíduos poluentes; a reciclagem de nutrientes, a diminuição da emissão de gases, fuligem e a eliminação das perdas de nutrientes, perdas atribuídas à queima da pal hada da cana-de-açúcar por ocasião da col heita.

\section{CONCLUSÕES}

1. A adição dematéria orgânica na lavoura decanade-açúcar por um longo prazo, através da preservação da pal hada por ocasião da colheita ou pela adição de vinhaça, alterou as propriedades químicas do solo e proporcionou melhoria na fertilidade do solo e na qualidade da matéria orgânica do solo com aumento do conteúdo de substâncias húmicas alcalinosolúveis mais condensadas.

\section{AGRADECIMENTOS}

Ao Técnico Agrícola Carmindo Afonso Filho, da UFRRJ -Campus, ea Leonel Miranda, pela indicação das áreas e pela ajuda na coleta das amostras de solo. AoSr. Fernando N eto, in memoriam, ea Arizolli Antônio Rosa Gobo. Ao CNPq (CER Proc. 521965/ 96-9) e FAPERJ , pelo auxílio financeiro.

\section{LITE RATURA CITADA}

ALEXANDER, M. Organic matter decomposition. In: ALEXANDER, M., ed. Introduction to soil microbiology. New York, J. Willey, 1977. p.128-147. 
ARAÚJ O, M.S.B. \& SALCEDO, I.H. Formas preferenciais de acumulação de fósforo em solos cultivados com cana-deaçúcar na região nordeste. R. Bras. Ci. Solo, 21:643-650, 1997.

BOLSANELLO, J . \& VIEIRA, J .R. Caracterização da composição química dos diferentes tipos de vinhaça da região de Campos-RJ . Bras. Açúc., 96:45-59, 1980.

BORGES, A.L. \& KIEHL, J.C. Alteração da matéria orgânica de um Latossolo Amarelo álico de Cruz das AImas (BA) pelo cultivo com frutíferas perenes e mandioca. R. Bras. Ci. Solo, 20:313-318, 1996.

CALASANS, C.V.C. Origem e dinâmica da matéria orgânica em um sistema fluvio-lacustre da região NorteF luminense. Campos dos Goytacazes, Universidade Estadual do Norte Fluminense, 1998. 100p. (Tese de Doutorado)

CAMARGO, F.A.O.; SANTOS, G.A. \& GUERRA, J.G.M. Macromoléculas e substâncias húmicas. In: SANTOS, G.A. \& CAMARGO, F.A.O., eds. Fundamentos da matéria orgânica do solo. Porto Alegre, Genesis, 1999. p.27-39.

CAMARGO, O.A.; BERTON, R.S.; GERALDI, R.N.\& VALADARES, J.M.A.S. Alterações de características químicas em um Latossolo Roxo distrófico incubado com resíduo deindústria deálcool açucareira. Bragantia, 43:125139, 1984.

CANELLAS, L.P.; BERNER, P.G.; SILVA, S.G.; BARROS E SILVA, M. \& SANTOS, G.A. Frações da matéria orgânica em seis solos de uma toposseqüência no estado do Rio de J aneiro. Pesq. Agropec. Bras., 35:133-143, 2000.

CERRI, C.A. Dynamique de la matiere organique du sol aprés défrichement et mise em culture. Utilisation du traçage isotopique naturel em ${ }^{13} \mathrm{C}$. Cah. ORSTOM., 24:335-336, 1988.

DABIN, B. Lès matièries organiques dans les sols tropicaux normalement drainés. Cah. ORSTOM., 17:197-215, 1981.

EMPRESA BRASILEIRA DE PESQUISA AGROPECUÁRIA EMBRAPA. Serviço Nacional de Levantamento e Conservação de Solos. Manual de métodos de análises de solo. Rio de J aneiro, 1979. Não paginado.

FREIXO, A.; MACHADO, P.L.O.A.; GUIMARÃES, C.M.; DIAS, C.A. \& FADIGAS, F. Estoques de carbono e nitrogênio e distribuição de frações orgânicas de Latossolo do cerrado sob diferentes sistemas de cultivo. R. Bras. Ci. Sol o, 26:425434, 2002.

GUERRA, J .G.M. \& SANTOS, G.A. Métodos químicos e físicos. In: SANTOS, G.A. \& CAMARGO, F.A.O., eds. Fundamentos da matéria orgânica do solo. Porto Alegre, Genesis, 1999. p.267-291.

GUERRA，J.G.M.; ALMEIDA D.L.; SANTOS G.A. \& FERNANDES M.S. Conteúdo de fósforo orgânico em amostras de solos. Pesqec. Agrop. Bras., 31:291-299, 1996.

KONONOVA, M.M. Materia Orgánica del suel o: su naturaleza, propiedades y métodos de investigación. Barcelona, Oikostau, 1982. 364p.

KORNDORFER, G.H. \& ALCARDE J.C. Acúmulo e teor de fósforo em folhas de cana-de-açúcar. R. Bras. Ci. Solo, 16:217-222, 1992.
LABRADOR, J. La materia orgánica en los agrosistemas. Madrid, Ministerio da Agricultura, Pesca y Alimentación, 1996. $174 p$

LEAL, J .R.; AMARAL SOBRINHO, N.M.B.; VELLOSO, A.C.X. \& ROSSIELO, R.O.P. Potencial redox e pH: variação em um solo tratado com vinhaça. R. Bras. Ci. Solo, 7:257-261, 1983.

MENDONÇA, E.S. \& ROWELL, D.L. Dinâmica do alumínio e de diferentes frações orgâncias de um latossolo argiloso sob cerrado e soja. R. Bras. Ci. Solo, 18:295-303, 1994.

MENDOZA, H.N.S.; LIMA, E.; ANJ OS, L.H.C.; SILVA, L.A.; CEDDIA, M.B. \& ANTUNES, M.V.M. Propriedades químicas e biológicas de solo de tabuleiro cultivado com cana-de-açúcar com e sem queima da palhada. R. Bras. Ci. Solo, 24:201-207, 2000.

MIELNICZUK, J. Matéria orgânica e sustentabilidade de sistemas agrícolas. In: SANTOS, G.A. \& CAMARGO, F.A.O., eds. Fundamentos da matéria orgânica do solo. Porto Alegre, Genesis, 1999. p.1-7.

ORLANDO-FILHO, J .; SILVA, G.M.A. \& LEME, E.J.A. Utilização agrícola dos resíduos da agroindústria cana-deaçúcarvieira. In: ORLANDO-FILHO, J ., ed. Nutrição e adubação da cana-de-açúcar no Brasil. Piracicaba, IAA/ PLANALSUCAR, 1983. p.227-264.

ORTEGA, F. La matéria orgánica de los suelos tropicales. La Habana, Academia de Ciéncias de Cuba, 1982. 152p.

RAIJ , B. van. Mecanismos de interação entre sol os e nutrientes. In: RAIJ , B. van., ed. Avaliação da fertilidade do solo. Piracicaba, Instituto da Potassa e F osfato, 1981. p.17-31.

RAMALHO, J .F.G.P. \& AMARAL SOBRINHO, N.M.B. Metais pesados em solos cultivados com cana-de-açúcar pelo uso de resíduos agroindustriais. Flor. Ambiente, 8:120-129, 2001.

RAVELLI NETO, A. Caracterização e classificação de uma seqüência de solos da Baixada dos Goytacazes. Itaguaí, Universidade Federal Rural do Rio deJ aneiro, 1989. 151p. (Tese de Mestrado)

REIS, R.A. \& MONNERAT, P.H. Diagnose nutricional da canade-açúcar em Campos dos Goytacazes (RJ -Brasil). R. Bras. Ci. Solo, 26:67-372, 2002.

RIO DE J ANEIRO. Lei n 2049, de 22 de dezembro de 1992. Dispõe sobre a proibição de queimadas de vegetação no estado do Rio de J aneiro em áreas e locais e dá outras providências. Diário oficial do estado do Rio de J aneiro, 18:1-23, 1992.

SCHNITZER, M. Soil organic matter - the next 75 years. Soil Sci., 151: 41-58, 1991

SCHNITZER, M. \& KHAN, S.U. Soil organic matter. Amsterdam, Elsevier, 1978. 319p.

SENGIK, E.; RIBEIRO, A.C. \& CONDE, A.R. Efeito da vinhaça em algumas propriedades de amostras de solos de Viçosa (MG). R. Bras. Ci. Solo, 12:11-15, 1988.

SILVA, A.J .N. \& RIBEIRO, M.R. Caracterização de um Latossolo Amarelo sob cultivo contínuo de cana-de-açúcar no estado de Alagoas: propriedades químicas. R. Bras. Ci. Solo, 22:291-299, 1998. 
SILVA, C.A.; ANDERSON, S.J . \& GUILHERME, L.R.G. Uso da cromatografia de exclusão por tamanho na caracterização de substâncias húmicas de L atossolo Vermel ho-E scuro sob efeito de calagem. R. Bras. Ci. Solo, 24:495-503, 2000.

SIQUEIRA, C.; LEAL, J .R.; VELLOSO, A.C.X. \& SANTOS, G.A. Eletroquímica de solos tropicais de carga variable: II. Quantificação do efeito da matéria orgânica sobre o ponto de carga zero. R. Bras. Ci. Solo, 14:13-17, 1990.

SPOSITO, G. Soil chemistry. New York, Oxford Academic Press, 1989. 227p.

TEDESCO, M.J .; SELBACH, P.A.; GIANELLO, C. \& CAMARGO, F.A.O. Resíduos orgânicos no sol e os impactos no ambiente. In: SANTOS, G.A. \& CAMARGO, F.A.O., eds. Fundamentos da matéria orgânica do solo. Porto Alegre, Genesis, 1999. p.159-196.
TESTA, V.M.; TEIXEIRA, L.A.J . \& MIELNICZUK, J . Características químicas de um Podzólico Vermel ho-Escuro afetadas por sistemas de culturas. R. Bras. Ci. Solo, 16:107114, 1992.

UNIVERSIDADE FEDERAL RURAL DO RIO DE J ANEIRO UFRRJ. Campus Dr. Leonel Miranda. Tecnologia canavieira nas regiões Norte Fluminense e Sul do Espírito Santo. Campos dos Goytacazes, Imprensa Universitária, 1999. 61p. (Boletim Técnico, 12)

ZECH, W.; SENESI, N.; GUGGENBERGER, G.; KAISER, K.; LEHMANN, J .; MIANO, T.M.; MILTNER, A. \& SCHROTH, G. Factors controlling humification and mineralization of soil organic matter in the tropics. Geoderma, 79:117-161, 1997. 